\title{
Internal Versus External Staffing in Nigeria: Cost-Benefit Implications
}

\author{
Francis C. Anyim (Corresponding author) \\ Department of Industrial Relations and Personnel Management \\ Faculty of Business Administration \\ University of Lagos, Nigeria \\ Tel: +23-480-334-68317_ E-mail: chucksanvim2004@yahoo.com \\ Cyril Oseloka Ikemefuna \\ Department of Industrial Relations and Personnel Management \\ Faculty of Business Administration \\ University of Lagos, Nigeria \\ Tel: +23-480-230-40845_E-mail: cyikem-unilag@yahoo.co.uk
}

\author{
A. Oluseyi Shadare \\ Department of Industrial Relations and Personnel Management \\ Faculty of Business Administration \\ University of Lagos, Nigeria \\ Tel: +23-480-3304-9507_ E-mail: seyidare2001@ yahoo.co.uk
}

Received: September 26, 2011 Accepted: October 13, $2011 \quad$ Published: December 15, 2011

doi:10.5430/jms.v2n4p35

URL: http://dx.doi.org/10.5430/jms.v2n4p35

\begin{abstract}
The internal recruitment is perceived in some quarters as the most favourite source of staffing an organization in stable and developed companies. The system needs a strong support from other HR processes in order to enhance morale and promote productivity otherwise it could yield disappointed and unproductive employees in the organization. Such HR processes include effective succession planning and consistent performance management to ensure success of the internal staffing. Though internal staffing may not bring new skills, competencies and fresh blood into the organization but it could build a strong loyalty as the employees have a chance to change their positions after a period of time and are not pressed to look for opportunities in the external labour market. The external recruitment on the other hand, brings new people to the organization. It allows the organization to define the right requirements especially where the labour market is full of potential candidates and to select candidates that best suit the organization's demands. There is no gain saying the fact that external staffing system with effective campaigning or advertisement could increase the popularity and enhance the image of the organization in the labour market, however, the system is expensive and takes a lot of energy from the HR functionaries in the course of handling job candidates in the selection process. In the light of the pros and cons of the two system of recruitment, this paper seeks to determine the cost benefit implications of internal vis-à-vis external system by considering the issues involved from four perspectives: economic, socio-psychological, financial and political context. It concludes that the usage of either internal or external staffing system to fill vacant positions should be determined by availability of qualified candidates, size of the organization and the desire to maintain and promote organizational culture.
\end{abstract}

Keywords: Internal Recruitment, External Recruitment, Human Resource, Staffing, Hiring, Labour Market, Selection 


\section{Introduction}

In an organization, employees are shifted up, down, across and out of the organization. The decision about internal staffing involves promotions, demotions, transfers and lay-offs which are an important aspect of human resource management. Effective internal staffing plans, policies and procedures will promote the achievement of both organizational and personal goals of individual employees while mismanagement of internal staffing may create a great deal of job dissatisfaction and reduce the effectiveness of the organization.

Several important factors influence internal staffing decisions. These include creation of new jobs due to growth and expansion of the organization. The filling of the new positions may result in promoting the existing employees. A major reorganization or restructuring may result in various types of personnel actions. For instance, to reduce personnel cost, top executive positions may be scrapped. This may bring about demotions, lay-offs, transfers as well as some promotions. An economic downturn like recession or depression could lead to loss of jobs by a good number of employees save those that work in what is termed as "recession proof" industries such as health-care and other essential services that may enjoy a stable or growing labour force through both good and bad economic periods. Voluntary and involuntary labour turnover and retirement can create vacancies that may be filled by promoting or transferring existing employees.

The organization's staffing system may develop in response to organization and human resource strategy or staffing considerations may serve as key inputs to organization and human resource strategy. When job vacancies occur or new jobs are created, is it advisable for the organization to sack incumbent or serving employees and fill the vacancies from the external or internal labour market? While some mixture of external and internal hiring will be necessary in most situations, the relative blend could vary substantially. To the extent that the organization wants to have a stable committed workforce, it will probably need to emphasize internal hiring. This will allow employees to use the internal labour market as a springboard for launching long-term careers within the organization. External hiring might then be restricted to specific entry - level jobs as well as newly created ones for which there are no acceptable applicants. External hiring might also be necessary when there is rapid organizational growth such that the number of new jobs created outstrips internal supply. According to Society for Human Resource Management (2000) an organization can decide to staff itself with people from within its borders, or it can supplement or replace such recruitment with employees recruited from other countries. As trading restrictions and immigration barriers are lessened, global staffing becomes a more distinct possibility.

\section{Literature Review}

Staffing should not be seen as a process of hiring people on a daily, weekly or monthly basis rather it is a process that establishes, and governs the flow of people into the organization, within the organization, and out of the organization. There are multiple, interconnected systems that organizations use to manage the flow of people. These include planning, recruitment, selection, decision-making, job offer and retention systems. For instance, if through manpower forecast there is increase in vacancies relative to established standards, the recruitment system will take over the task of generating more applicants. The selection system will handle the volume of applicants that need to be evaluated or screened and choice made. Top management of the organization decides on the packages to be offered in order to entice qualified applicants; further steps will have to be taken in trying to retain the new employees in order to avoid having to repeat the above experience in the next staffing cycle or exercise.

Large organization with relatively high labour turnover may find they need to cast much broader net. The decision of breadth versus depth comes down to the number of individuals who need to be hired, the recruiting budget, and a strategic decision about whether to invest deeply in a few programme or more broadly in more programmes. Another decision that can be made is which colleges and universities to target. According to Mullich (2004) the factors to consider include: past experiences with students of various schools, rankings of school quality and costs of recruitment.

For higher level professional positions or jobs, executive search firms or 'headhunters' are used by companies. However, experience in the recent time has shown that business has been slow for the executive search firms partly due to the moderate economic growth and bustling on line recruiting business. That means that companies are able to negotiate smaller fees retainers or contingencies (Mchain, 2002). Executive search firms are also engaged by some organizations to conduct staff appraisal exercise.

This actually makes sense as both recruitment and appraisal exercise centres on assessment. However, a situation may arise where the search firm could have an incentive to pronounce an in-house executive or top management staff incompetent or inefficient so as to justify bringing in an outsider or external candidate, thereby benefiting for being contracted to handle the hiring. Given this inherent conflicts of interest, Gomes (2002) lays emphasis on the need for 
organizations to avoid using the same company to hire new executives and also appraise its existing top management team.

Internship is another medium of staffing an organization as it allows students to have an employment with an employer for a specified period of time. The approach assists the organization to obtain services from part-time employees for a short period of time but they also allow the organization the opportunity to assess the person for a full-time engagement after graduation. Working with intern is one of the best talent search opportunities available to managers (Hymowitz, 2000). Occasionally, experience had shown that some internship do not provide high utility to organizations in terms of the benefit - cost ratios. Thus organizations need to evaluate internships not only in terms of the quality of the students but from a cost-benefit economic perspective as well (Bassi and Ludwig, 2000).

With respect to advertisements for job openings especially for external staffing, organizations that wish to place and portray an appealing message to potential applicants may develop an employment brand which focuses on good company tag that places the image of the organization as being great and attractive enterprise to work or an employer of first choice. As adduced by Lieven and Highhouse (2003) empirical evidence had shown that having an employment brand can attract applicants to an organization, even beyond job and organizational attributes. Furthermore, employers are most able to get their brand image out when companies engage in early recruitment activities such as advertising or generating publicity about the company. One way to improve matching people with jobs is to target the recruitment message to a particular audience. Different audiences may be looking for different rewards from an employer. University, graduates appear to be attracted to organizations that provide rewards and promotions on the basis of individual rather than group performance. Also, they prefer to receive pay in the form of a salary rather than incentives (Thorsteinson, Billings, and Joyce, 2001).

The objective of the internal recruitment process is to identify and attract applicants from among individuals already holding jobs with organizations. Many recruiters from discipline outside Human resource management may not have any specialized training in Human resource issues hence the training of recruiters is imperative. Unfortunately, very few recruiters even receive any training. Based on current organizational practices, recruiters should receive training in the following areas: interviewing skills, job analysis, interpersonal aspects of recruiting, laws and regulations, forms and reports, job characteristics and recruitment targets (Calandra, 2000). Under a targeted system of recruitment, both open and closed steps are used simultaneously. Jobs are posted and human resource department conducts a search outside the job posting system. This is to ensure that viable candidates are identified. Jobs posted internally are done to ensure that internally interested or perhaps overlooked employees can apply (Cook, 2000). Web-based recruitment offers many advantages to employers. Many people can be reached. It is particularly important when filing large numbers of positions and also when the labour market is both national and international or when the unique nature of those needed requires casting a wide net. It is not unlikely that the web can be a sole source for recruiting applicants. The costs of internal recruiting must be weighed against the benefits, including the number of qualified applicants relative to quality of those applicants and other criteria such as offer acceptance rates, turnover etc (Starner, 2001).

An intranet though confined to the organization can be used by managers to source for internal talents. It makes sure that interested employees get personal attention and given equal opportunity like the external candidates-even if they are not selected (Frase-Blunt, 2004). It may also be pertinent to state that aside from hiring new talent through normal staffing systems, it might be possible to acquire it en masse through a merger or even acquisition (Marke and Marvis, 2001).

\section{Internal Staffing Sources and Policies}

Promotion involves the reassignment of an employee to a higher-level job. When an employee is promoted, he faces increasing demands and challenges in terms of efficient skills utilization and enormous responsibilities. In return or as a means of compensation, the employee receives increased pay and benefits as well as greater authority and status. Promotion serves many purposes and provides benefits to both the organization and the employees. Promotion enables the organization to utilize its employees' abilities to the fullest or greatest extent possible. An effective system of promotion allows the organization to match its continuous need for competent staffs with the staffs' desires to apply the skills they have acquired. Promotion can encourage high performance since it is a source of motivation to the employees. In sum, an effective system of promotion can lead to greater organizational efficiency and high level of employee morale.

There are a number of criteria organizations apply in deciding which employee to promote. Many employers place significant weight upon an employee's seniority when making a promotion decision. Seniority is directly related to an employee's length of service and has long been an important criterion in many organizations. Use of seniority has some drawbacks. Some of the employees with short length of service may lose motivation if their high performance does not count in getting a promotion. Also career-oriented employees may become impatient waiting for a promotion and seek 
employment in organizations that base promotion on performance. However, the strongest argument against using seniority as a criterion is that the senior employee may not be qualified for the job. Length of service may have little bearing on the kind of skills and abilities required to assume a new position.

Due to the drawbacks in using seniority as a promotion criterion, many organizations greatly consider current performance when promoting employees to jobs with high responsibilities, especially in professional jobs. Seniority is less significant in cases of this nature but rather the employee's performance appraisal, training and development, special awards, commendation(s), achievements and other performance data are often combined to determine the employee's chances for success in a higher job. Using past work performance would be a fairly good predictor of future success in performance but past performance is not always a valid indicator of future performance, particularly when the employee is promoted to a job that requires skills and abilities considered different from those used in the previous job.

Promotion is not the only sources of movement for an employee within the organization, a demotion which is the reassignment of an employee to a lower job with less pay and also involving lower skills and responsibilities can occur. Demotion may take place for reasons beyond the control of the employee. Major changes such as reorganizations, company merger or business contraction may result to fewer jobs, forcing some employees to accept lower positions. In a situation like this, some employees may be demoted with the stigma attached to demotion being minor. In other situations, an employee may be demoted for inability to perform his job according to acceptable standards. Here, the demoted employee's frustration, resentment, anger and fear can continue for a considerable length of time. Therefore, when demotion is viewed as a devaluation of personal worth, the psychological damage can be significant. However, demotion is not an effective way to handle disciplinary problems rather it will aggravate the problem. Perhaps, a more meaningful and equitable approach could be to keep the employee in the present job but reassign or curtail his authority and responsibilities and same passed to other employees.

Another source of internal staffing is transfer which is the reassignment of an employee to a job with similar pay, status, duties and responsibilities. A promotion involves upward movement while a transfer involves a horizontal movement from one job to another. Transfer takes place for several reasons. Firstly, it could be due to faulty placement of an employee on a job. The transfer serves to move the employee to a more suitable job. Second, an employee may become dissatisfied with the job for one or a variety of reasons: serious conflict or disagreement with co-workers or his superiors; poor performance; lack of interest or job satisfaction, etc. thirdly, the organizations sometime initiate transfers to further the development of the employees. The transfer could involve a job on same title but in another setting or environment with an interaction with new set of employees or with unique problems. Voluntary or involuntary labour turnover, promotions, demotions and termination may result in job vacancies that may be filled most effectively through the process of transfers.

Internal staffing could result due to layoff. Economic downturn or recession creates economic problems and the outcome hits the employees the hardest in form of layoff. A layoff reduces surplus employees from the organization's payroll. Seniority plays a major role in determining the order of layoffs. For instance; the principle of LIFO (Last in, first off) plays a prominent role in this respect. Apart from seniority criterion, other criteria are used in deciding which employees to lay off: performance, age and political considerations.

Many of the human resource management problems could be resolved through sound internal staffing policies and practices. In a situation where the employees hold the perception that their skills are being disregarded or underutilized, dissatisfaction and labour turnover are likely to occur. Furthermore, when employees perceive that they are being treated unfairly or discriminated against, they may not show commitment and loyalty to the cause of the organization. The foregoing situations reflect a lack of concern for human resource and reduce the organization's effectiveness. Therefore, human resource managers must create and implement internal staffing practices that are fair and that make the greatest use of employees' abilities.

It is likely that the most prudent approach in filling job vacancies is to adopt a policy of promotion from within but to maintain enough flexibility to tap the external labour market when employees within the organization are not qualified. To support a policy of promotion from within the organization, the human resource manager must be in a position to determine the promotability of employees within the organization. The quality of the information used will affect the quality of decisions made on staffing matters. Managers must ensure that the performance appraisal systems generate data that accurately reflects the employees' achievements and shortcomings. Management by objectives and behavioural systems approach of performance appraisal system could be used to minimize bias and subjectivity of rating scales and better decisions enhanced. Therefore, human resource managers owed it a duty to adopt a system that will provide accurate measure of employees’ performance. 


\section{External Staffing and Sources}

Every organization regardless of size, product or service must recruit applicants to fill vacant positions. Recruitment is the process of employing applicants who are available and qualified to fill vacant position in the organization. When positions become vacant, the human resource manager can fill such positions through direct applications from individuals, by walk-in applicants, newspaper advertisement or through the organization maintaining a large pool of available and qualified applicants without much additional recruitment effort. The people most available for recruitment are the unemployed who can be contacted through direct application, employment agencies or exchange, or by advertisements.

The objective of external staffing process is to identify or attract job applicants from outside the organization. From among these applicants, hiring decisions are made. The recruitment process begins with a planning phase during which both organizational and administrative issues, as well as those pertaining to recruiters are addressed. Organizational issues include in-house versus external recruitment locations, individual versus co-operative recruitment alliances, and centralized versus decentralized recruitment function. Administrative issues include requisitions, timing, number and types of contracts, the recruitment budget and development of recruitment guide. Finally, the selection, training and compensation of recruiters must also be planned and executed. The next step focuses on recruitment strategy in order to ascertain where and how to look for qualified applicants. Determining where to hire qualified applicants requires a good understanding or knowledge of open and targeted recruitment strategies. It also involves the knowing of recruitment sources and deciding which one to use. When strategy has been formulated, the message to be communicated to job applicants is established and the communication medium to use should be decided.

Once management has determined an organization's staffing position, the first decision made is whether the job opening should be filled by someone already employed or by an applicant from outside (externally). In each case, the advantages of recruiting outside the organization must be weighed against the advantage of recruiting within or inside the organization.

External source of recruitment involves the recruiting of a greater number of applicants from outside who may bring in new ideas, work techniques and training, all in a bid to increase the productivity of the organization.

In sum, sources of recruitment are: applicants with write-in applications; advertisement through mass and electronic media; employment agencies; colleges or tertiary institutions placement; walk-in applicants; or through employee referrals.

There are some alternatives which an employer can adopt as an alternative to recruitment, though they appear to be short-term measures. Existing employees could be granted overtime to meet production target. Temporary or part-time employees could be engaged and discharged when pressure reduces. The employer can use employee leasing which involves hiring employees with certain skills and abilities from an external consultant or a leasing company under a specified contract terms.

\section{Assessing the Effectiveness of Recruitment Process}

Many aspects of recruitment such as the effectiveness of recruiters can be evaluated. Organizations assign goals to recruiting of various types of employees. For example, a recruiter's goal might be to hire 500 unskilled and semi-skilled employees or 100 technicians or 50 machinists or 150 managerial employees per year. The organization can decide which of the organizations (consultancy firms) that is the best. This can be done by determining those who meet or exceed their quota and those whose recruits stay or remain intact with the organization and are evaluated well by their superiors or supervisors.

Sources of recruitment can also be evaluated. In higher institutions recruitment, the organization can divide the number of job acceptances by the number of campus where interviews took place to compute the cost of hire at each institution. The computation will drop from the least campuses that are not productive.

The methods of recruitment can be evaluated by various means. The organization can calculate the cost of each method (such as advertisement) and divide it by the benefit it yields (acceptance of jobs/offers). After the interview, the organization can also examine how much accurate job information was given by the applicants during the recruitment process. Another aspect of recruitment that can be evaluated is what is termed as "quality of hire". This measure provides management with an assessment of the quality of new employees being recruited and hired.

The quality of hire measure is calculated mathematically thus:

$\mathrm{QH}=\mathrm{PR}+\mathrm{HP}+\mathrm{HR} / \mathrm{N}$

Where: 
$\mathrm{QH}=$ Quality of recruits hired.

$\mathrm{PR}=$ Average job performance rating. (20 items on scale) of new hirees. For example, 4 on a 5-point scale or 20 items $\mathrm{x}$ $4=80$.

$\mathrm{HP}=$ Percentage of new hirees promoted within one year e.g. 35\%

$\mathrm{HR}=$ Percentage of hirees retained after one year (e.g. 85\%)

$\mathrm{N}=$ Performance and promotions are variables beyond the control of a recruiter.

Note: Performance and promotions ratios are variables beyond the control of a recruiter.

\section{Selection Process}

Recruitment is the activity that generates a pool of applicants who have the desire to be employed by the organization from which those suitable can be selected. Selection on the other hand, is the activity in which an organization uses one or more methods to assess individuals with as view to making a decision concerning their suitability to join that organization to perform tasks which may or may not be specified. The selection process pulls together organizational goals, job designs, and performance appraisals as well as recruitment and selection. The first element in the selection process is the setting of organizational goals which must include recruitment policy of the organization. The policy must determine how the employees fit into the overall framework of the organization and it must establish the relationship among the employees in the organization. The second element in the selection process involves job design which has to do with the determination of what duties and responsibilities each job will entail. The job has to be designed in such a way that it has positive effect on performance and motivation.

The third element involves the measurement of job success.

The revelation on which employees were successful will determine what kind of employees to recruit and select in the future. The fourth element is job specification which emanates from job analysis. This specifies what traits, skills and background an individual must have to qualify for the job.

Finally, the policy must state or determine which combination of interviews, test or other selection devices to use in the selection process. However, there is no special combination of selection instruments which will minimize the cost of selection and facilitate choosing the best candidates available.

The steps in the selection process vary from one organization to the other. The sequence may vary according to the type of jobs being filled and the size of the organization. The process usually begins by reviewing current applications received through the process of recruitment. Applicants who seem to be qualified for the position are then screened. The applicants are made to complete application blank which supplies detailed information about them. If considered necessary, tests relevant to the job and validated by the organization are then administered on the applicants. The next step is usually to interview the applicants. The background of desirable applicants is checked especially their references and employment history. Finally, the few applicants who survive the last stage are interviewed by the departmental heads or supervisors. During this in-depth interview, job requirements are discussed so that the applicant as well as the departmental head will be able to judge each other's interest in the job. At this point, a job offer can be made to the applicant best qualified for the job. If the applicant rejects the offer, management can then either contact other qualified applicants or begin the recruitment process over, if there are no other qualified applicants available. When the applicant accepts the offer, the next stage involves the placement of the applicant on the job.

\section{Cost-Benefit Implications of Internal Versus External Staffing}

To examine the cost-benefit implications of internal and external staffing, we shall approach the issue from four perspectives: economic, socio-psychological, financial and political context. With respect to the economic dimension, internal staffing will involve limited cost of hiring. Learning or on-the-job training is a continuous process for the employees with no cost attached to it or to the organization. Training needs to internal employees are less pronounced. The internal employees can adjust faster or at ease on the job in the event of transfers, redeployment to new station or location as manpower needs dictates.

In sum, efficiency and enhanced productivity can be guaranteed. Cost of hiring external employees on the other hand will be high or expensive. A lot of time will be utilized on learning or induction process before the new employees settle down and become productive. The new employees require a lot of training which will be expensive or costly in monetary terms. It will take the new employees time to adjust to their new job and the environment.

Hiring of employees from external source will give room for selection to be made from a larger pool of qualified applicants. The new employees may bring along new ideas, work techniques or production methods to the organization 
which could result in increased productivity. New employees may also have contacts which internal employees may not have in the areas of marketing, research or technology.

The second dimension focuses on socio-psychological factors affecting the two types of staffing system under discourse. Promotion which involves movement or advancement from a lower to a higher status for the internal employees will heighten morale and pose a challenge which serves as a source of motivation to the employees. Having put in a good number of years in the organization, the employees will have a stake in it which will in turn promote loyalty and commitment to the cause of the organization. Promotion within the organization will lead to a vacant position which can then be filled within the organization. Thus, the chain effect of promotion will serve as a morale booster to internal employees since each promotion positively affects several employees. Promotion within the organization ensures that unknown persons are not used as experiment at higher levels which can have adverse effect on the well-being or health of the organization. The individuals, therefore, are given the opportunity to prove themselves at lower positions before elevation. Due to the fact that the organization keeps record on every internal employee, rewarding successful performers will be faster and less expensive to determine. By so doing, internal staffing can save money and time. External staffing will involve the engagement of pool of new employees or entrants with no stake in the organization. Lack of stake in the organization can lead to the problem of loyalty and less commitment to the organization. Some of the internal employees who have spent a good number of years in the organization may be faced with the problem of obsolescent skills because of reluctance in improving their educational background and this can lead to their discharge or lay-off from the organization. External staffing, however, has the advantage of eliminating the foregoing situation on obsolescent skills and attendant check out from employment since new employees will be engaged on positions commensurate with their educational attainment or skills hence the threat or fear of unexpected discharge is lessened. Promotion though heightens the morale of the internal employees, but could as well create room for poor attitude to work amongst the employees who may perceive that they have been duly denied of promotion by the organization. In similar vein, promotion can lead to "Peter principle" which is a situation in which an employee can be promoted beyond his or her level of competence. External recruitment can eliminate or serve as a check against 'Peter principle' and also the placement of the internal employee on acting capacity for a specified period can check Peter Principle.

Turning to the financial context which is the third dimension, internal staffing matched with increase in job satisfaction, perception of high stake in the organization and promotion of employees as and when due will create stability in labour turnover and in sum translate to high labour costs in terms of high remuneration package and settlement of terminal benefits (Gratuity and Pension). External staffing on the other hand, may not attract high labour costs in comparative terms since the employees will start on a lower entry point in the salary scale and it will take them a long time to qualify for payment of gratuity and pension (terminal benefits). Also, the external employees have to work for some time before they are considered eligible for promotion. The fourth dimension has to do with political factors inherent in the workplace. Filling of vacant position internally can result to internal squabble and in-fighting amongst the various ethnic groups within the establishment. Employees not selected can adopt poor attitude to work and this can stifle creativity and new ideas. The adoption of quota system in line with the directives of the government could breed political in-fighting due to the distortion that will be created in the placement of the internal staff. The adoption of the "catchments principle” within an establishment could create similar problem for internal staffing. For instance, with the creation of new states in Nigeria, there have been instances when staffs working in the older states were asked to leave their current position and take up new employment in their states of origin. The displacement caused by this trend has its attendant problems for internal staffing. Filling of vacant positions caused by the creation of more states could lead to Peter principle. External staffing in the circumstance under discussion can reduce internal squabble and political wrangling since the new employee will be engaged absolutely on merit. In the course of recruitment, the quota system and catchment principle will be taken into consideration in making final selection or decision on the new employees. External staffing gives the establishment the opportunity of recruiting a new employee or a beginner with no political leaning, intrigue or pollution of mind. External staffing will also be useful in the newly created states for the infusion of new ideas since internal staffing alone may not be able to cope with all the needs of new states.

\section{Conclusion}

In this discourse, efforts were made to examine the cost-benefit implications of internal and external staffing from four different perspectives. From the economic plane, internal staffing attracts limited cost of recruitment when compared with external staffing. Efficiency on the job by the internal employee enhances productivity whilst external staffing will involve learning or induction process and time to settle down and become productive on the job.

Turning to the socio-psychological angle, elevation on the job induces high morale or motivation which imposes greater challenges on the internal staff. Perception of high stake in the organization induces loyalty and commitment to the 
cause of the organization. To the external and new employee, he has little stake in the organization and his loyalty may be in doubt as his job behaviour is precisely not known. The problem of reliability and integrity may set in.

In the financial context, it is true that internal staffing will attract high labour costs for reasons already adduced whilst external staffing will attract lower labour costs but if the labour costs are tied to the level of productivity of each group, the internal employees in terms of their training, duration of stay, experience on the job, loyalty and commitment will be more productive than the external employees hence justification for the high labour costs.

From the political context, internal staffing can ginger hostile atmosphere as a result of political wrangling which the external staffing can check or minimize but there is no straining the fact that external staffing cannot cope with some staffing needs such as transfers caused by creation of new branches, market outlets or new states. In this regard, internal employees will be faster in setting up administrative machinery in the new location than the external and new employees who may not be familiar with the culture of the organization.

In conclusion, whether employees are recruited from within or outside should be determined by the availability of qualified employees in the organization, the size of the organization and the desire to keep up with contemporary ideas and methods. It should be realized that external recruitment does not mean in all cases that no one is qualified to fill the position internally rather it indicates the need for fresh ideas and new strategies or approaches to organizational or corporate problems.

\section{References}

Bassi, L. J. \& Ludwig, J. (2000). School to Work Programmes in the United States: A Multi-Firm Case Study of Training, Benefits and Costs. Industrial and Labour Relations Review (53).

Calandra, B. (2000). Reeling them In. Human Resource Executive, Sept.

Cook, J. (2000). Crossover Success. Human Resource Executive Sept.

Frase-Blunt, M. (2004). Intranet Fuels Internal Mobility. EMT, Spring.

Gomes, L. (2002). Executive Recruiters Face Built - In Conflict Evaluating Outsiders. Wall Street Journal, October, $14^{\text {th }}$.

Hymowitz, C. (2000). Internship: A Tight Job Market, College Interns Wooed. IPMA

Lievens, F. \& Highhouse, S. (2003). The Relation of Instrumental and Symbolic Attributes to a Company's Attractiveness as any Employer. Personnel Psychology (56).

Marke, M. I. \& Marvis, P. H. (2001). Making Mergers and Acquisitions Work. Academy of Management Executive, 15(2).

Society for HRM. (2000). Globalization of the HR Profession. Workplace Visions.

Starner, I .T. (2001). College Recruitment Goes for Niches. Workforce Management, February.

Thorsteinson, T. J., Billings, M. A. \& Joyce, M. C. (2001). Matching Recruitment Messages to Applicants Preferences. Poster Presented at $16^{\text {th }}$ Annual Conference of Society for Industrial and Organizational Psychology, San Diego. 